\title{
English Translation of Chinese Tourism Text: Text Function Perspective
}

\author{
Jingjing Jia \\ Zhangjiagang Campus, Jiangsu University of Science and Technology, Zhangjiagang 215600, \\ China \\ jingjingjia0121@hotmail.com
}

\begin{abstract}
Keywords: tourism text, text function, directive function, informative function, descriptive function
\end{abstract}
\begin{abstract}
This paper, evolved around three functions in tourism text, is intended to explore the English translation of Chinese tourism text from the perspective of text function. In this process, the paper attempts to find out the effective translation methods applied to the tourism translation so as to offer insights into tourism translation and enlightenment to the further study in this specific field, and also test the applicability of text function in tourism text and other texts.
\end{abstract}

\section{Introduction}

English translation of Chinese tourism text, as a window to foreign publicity has become an important part of tourist strategy and has gradually drawn many scholars' attention. The increasing interest in tourism has heightened the need for the study of tourism English translation.

Tourism translation, aimed at attracting visitors abroad, attaches great emphasis on the readability of the translated version. Some of the existent translations do achieve this purpose and at the same time help win millions of visitors abroad. However, some are far from being satisfactory. Spelling errors, grammar mistakes and inappropriate usage of vocabulary, etc often appear in the translation. Sometimes, there are even serious mistakes in the translation. All of these have negative effect on the development of tourism industry and will, to some extent, damage the image of the scenic spot introduced or even the image of our country. Since tourism translation is so important, it is imperative that we should do something to improve the quality of its translation.

\section{Contrastive On the Function of Chinese and English Tourism Text and Translation Methods Applied in English Translation of Chinese Tourism Text}

\subsection{Purpose and Function Analysis of Tourism Text}

To serve visitors better, the tourism text, be original or translated version, should meet visitors' need, which leads to the three purposes of tourism text. The main and most important purpose is to attract the visitors' attention, arouse their interest, and induce them to take positive response and visit a particular scenic spot.

Another purpose of tourism text is to provide adequate information to visitors during their trips. The information includes introductions of the scenic spot, the uniqueness of certain scenery, and transportation, services available, etc. In a word, tourism text aims to offer different kinds of guidance to tourists when they travel.

The other purpose tourist text possesses is to spread culture. Every nation has its unique culture and tourists are usually excited at the otherness of the places they visit. Tourism text caters to people's need and arranges cultural information in its content so that visitors can not only get some information about tourist spots but also acquire some cultural information and learn more about the history and culture of the spots.

In accordance with the three purposes and referring to the classification made by Li Yunxing[1], tourism text usually carries three functions: informative, descriptive and directive.

Informative function is the basic function of tourism text and it means that a text should have the function of providing visitors with both rich practical tourist information such as location, tour route, facilities, services, and charges and human information such as culture, customs and history etc. 
Descriptive function is another indispensable function of tourism text because tourism text with only informative function, no doubt, can not attract visitors only by providing simple information like transportation or location. According to Li Yunxing "the descriptive function of a text is to describe the static images of certain object's appearance or state, etc. The realization of descriptive function lies in the completion of three aspects: in terms of textual function, it depends on the orderly arrangement of spatial sequence; in terms of diction, it relies on the use of descriptive words such as adjective, adverb, verb, etc; in terms of communicative participator, it depends on the use of the participator's visualization." In terms of tourism text, only the first two are employed.

Directive function is the most important function among the three. As Li Yunxing mentions that "directive function, as performed by a suggestion, a request, or a command, etc., is that of getting the listener to do something." And Hu Zhuanglin also points out: "When the language is used to get the hearer to do something, it serves a directive function."[2] "In a word, directive function of a text is to bring about perlocutionary force by means of issuing an order or attractive information." as stated by Li Yunxing. As far as tourism text is concerned, its perlocutionary force is to motivate and persuade visitor to make their decision, that is, to visit the place introduced. Owing to the fact that tourism text aims to please visitors and attract them to certain scenic spot, directive function should be regarded as the most important function employed in tourism text.

The three functions are closely interrelated and are all of great importance to tourism text. The relationship between them should be understood as: the informative and descriptive functions are the premises, while the directive function is the ultimate purpose. Therefore, informative and descriptive functions are supplementary functions and do not occupy the whole text while directive function is, on the opposite, the leading function and runs through the whole paragraph.

\subsection{Contrastive Study on the Function of Chinese and English Tourism Text}

It is natural that Chinese and English tourism text should have the same text functions because both of them belong to the same kind of text. However, as two different languages, they also have great difference in expressing ideas, even the same idea. That is to say, Chinese and English will use different methods to achieve the same function.

Both Chinese and English tourism text have informative function, but they differ in the way of achieving it. The greatest difference is the content included. Generally speaking, Chinese tourism text contains much more cultural information than English one. When introducing a scenic spot, Chinese tourism text focuses on scenery and cultural characteristics of tourist resources such as historical development, social impact, and detailed description of scenery, etc. While English tourism text focuses on pure information delivery of tourist resources such as location, services, transportation etc. with relatively few lines of description on scenery or on the history or social impact.

The realization of descriptive function depends mainly on the spatial sequence and descriptive words. To arrange a text in a spatial sequence is to present a clear picture before its readers, which is employed by Chinese tourism text as well as English tourism text. The difference in the use of descriptive words between Chinese and English tourism text is mainly reflected in word diction: one prefers four-character phrases, the other prefers one single simple word; and one likes using abstract words to express idea, the other like specific words to express the same idea, which makes the translation between them sometimes seems to be impossible.

Directive function is the most important function in Chinese tourism text as well as English tourism text. It can be achieved by two means: direct directive function and indirect directive function. The realization of the former is similar both in Chinese and in English tourism text. However, the latter-indirect directive function is realized differently in Chinese and English text, especially in stylistic method and expressive languages. As to stylistic method, Chinese text usually begins with giving detailed information such as description of statements of reasons or detailed facts and then is followed by generalizing the whole text with a conclusive sentence or sentences in the end.That is to say, Chinese develops a text in the way of induction. While in English, the most important information is normally put at the beginning of a sentence, and then supported by the description of specific details or evidences, which is called deductive method. As far as expressive languages are concerned, 
Chinese tourism text often quotes copiously from many sources in order to add literary flavor, while this method is absent in English tourism text due to cultural and historical reasons.

\subsection{Translation Methods Applied in English Translation of Chinese Tourism Text}

The translation of these three functions should be first of all visitor-centered, a term originated from Nida's reader-centered. The foreign visitors' thinking pattern, reading habit and aesthetic standard should be the first priority in translation. In order to achieve the final directive function, different translation methods should be adopted to fulfil the three functions and achieve the ultimate purpose.

Direction function in tourism text takes the responsibility of attracting visitors, so to translate a text with directive function is not an easy job and should always be visitor-centered and conform to the convention of visitors. Just as Li Yunxing proposes "whether a text successfully exerts its directive function or not must be judged by the effect of the text on the reader and the reaction of the reader." Therefore, during the translation, some necessary translation methods such as adjustment, rewriting and remolding should be employed in order to cater to visitors' aesthetic standard or thinking pattern to achieve directive function.

Informative function, as supplementary function, is responsible for providing visitors with abudant information and supports the main function-directive function. That means as long as the directive function can be achieved and the text is understandable to readers, it is unnecessary to do the wordfor-word translation. Different from English toruism text, Chinese text not only includes information such as location, transportation and services available, most importantly, it contains unique cultural information. Therefore, in the translation, cultural information should be handled flexibly and some translation methods such as addition and explanation can be adopted to keep the cultural flavor so as to help to realize directive function.

Descriptive function, like informative function, also aims to reproduce the directive function in the translated text. To realize descriptive function, in translation, some translation methods such as specification and generalization should be used, that is, to specify or generalize some four-character collocations, parallel structures, some rhetorical devices, and descriptive words which are common in Chinese tourism text to avoid the invalid translation in English.

\section{Literature References}

In the last decade the study of translation has drifted away from linguistic and literary approaches, moving towards discourse, textual and cultural perspectives, not to mention genre, gender and even postmodernist viewpoint. The studies conducted have definitely exerted great influence on general translation theory, enabling the discipline to broaden the areas of investigation and to offer fresh insights into the translation of different specific fields, namely the study of the tourism translation.

The studies on tourism translation abroad mainly adopt linguistic approaches such as speech act theory proposed by Leo Hickey[3] in his article "Perlocutionary Pursuits: Persuading of/that/to", genre analysis raised by Rosa Lores Sanz[4] in "Thematic Patterns in Tourist Literature: an Approach to the Study of Genre", etc. Linguistic perspective offers insights into English tourism translation and enlightenment of the further study on this specific field. While the studies at home covers a relatively wider scope ranging from linguistics, culture to aesthetics. Lu Jianping and Jian Qingmin[5], and Ye Miao[6] studied tourism translation from linguisitic perspective in their articles "Analysis of Pragmatic Failure in Tourism English" and "Pragmatic Translation of Tourism Materials". And Gao Jinling, Jia Wenbo and Ma Songmei conducted researches from aesthetic perspective. In addition, many sholars and translators such as Yang Zhenjie, Fu Wen, Lai Shaohua and Zhu Yiping concentrate on the influence of culture on tourism translation.

However, the previous researches and studies suffer from some limitations. On one hand, most articles and documents of tourism translation available mainly focus on syntactic or semantic level, regarding translation as static terminal product and confining their discussion to the name of scenic spots, place name, slogan, course name, culture-loaded words or error analysis of individual sentence, which is far from enough to provide satisfactory strategies to translation study as far as tourism translation is concerned. On the other hand, many studies have been conducted to explore the purpose 
of translation or translator, but few studies have attached importance to the function(s) carried by tourism text.

The present paper eliminates these two limitations by taking the whole tourism text as the subject of study and studying it from text function perspective. Taking the whole text into consideration is because translation goes far beyond the syntactic level and concerns the whole text. "Translations are texts, and translation is a textual process in which linguistic form and process are incorporated.... The text has to be considered the primary object of translation study."as stated by Neubert [7] To study tourism translation from text function perspective offers a new angle of study and will provide some enlightenment to the scholars and translators to facilitate the study of tourism translation.

\section{Summary}

Many scholars have conducted various researches and studies at every level from different angles to probe into the possible theoretical framework or translation methods for English translation of Chinese tourism, but few has completed comprehensively and thoroughly.

This paper attempts to define three text functions included in tourism text and in doing so, it also explores the effective methods applied to the translation of tourism text. By applying the proposed translation strategies, the author believes that this research will be helpful to the improvement of the Chinese-English translation of tourism text. In addition, it will give some insights to the training of our guide interpreter or translation teaching practice.

However the present paper also has some limitations. Firstly, the study may, in some sense, not be absolutely objective because it is hard to make a contrast study between different English versions due to corpus shortage, especially shortage of different English versions of the same Chinese tourism text. Besides, the paper does not make a further study on the inner characteristics of tourism text such as semantics, syntax, cohesion and coherence model, etc.

All in all, translating tourism text from Chinese into English is a rather complicated task. And the author calls on an earlier establishment of standardization for the translation in this field. Since its translation involves various factors to be considered, it is impossible to analyze all of those in one paper. In addition, due to limitation of my knowledge and the lack of relevant materials, I am sure that my discussion in this paper is not fully developed, which needs to be improved in many aspects.

\section{References}

[1]. Li Yunxing. An Introduction to Pragmatic Translation. Beijing: China Translation \& Publishing Corporation, 2003, p.11-89.

[2]. Hu Zhuanglin. An Introduction to Linguistics. Beijing: Beijing University Press, 1997, p.10.

[3]. Hickey, Leo. Perlocutionary Pursuits: Persuading of/that/to. Pragmatics at Work: The Translation of Tourist Literature. Bern: Peter Lang AG, European Academic Publisher. (2004), p.57-81.

[4]. Sanz Lores Rosa. Thematic Patterns in Tourist Literature: an Approach to the Study of Genre. Pragmatics at Work: The Translation of Tourist Literature. Bern: Peter Lang AG, European Academic Publisher. (2004), p.103-157.

[5]. Lu Jianping and Jian Qingmin. Analysis of Pragmatic Failure in Tourism English. Foreign Languages and Their Teaching. Vol. 9(2001), p. 23-25.

[6]. Ye Miao. Pragmatic Translation of Tourism Materials. Shanghai Journal of Translators. Vol. 2(2005), p. 26-29.

[7]. Neubert, Albrecht, \& Gregory, M. Shreve. Translation as Text. Kent: The Kent State University Press, 1992, p. 10. 